\title{
Modelando a Ação das Respostas Humoral e Celular Contra a Infecção por Rotavírus ${ }^{1}$
}

\author{
A. PINHEIRO ${ }^{2}$, H.M. YANG ${ }^{3}$, DMA, IMECC, Lab-Epifisma, UNICAMP, Cx.P. \\ 6065, 13083-859 Campinas, SP, Brasil.
}

\begin{abstract}
Resumo. Os rotavírus são considerados, atualmente, um dos mais importantes agentes causadores de gastroenterites e óbitos em crianças com menos de 5 anos no mundo. Ocorrem globalmente cerca de 125 milhões de episódios diarréicos por rotavírus a cada ano. Esses números alarmantes estimularam a busca por um controle desse vírus, mas para combatê-lo é necessário estudar seu comportamento, como ele penetra no organismo humano, como age dentro dele e como se espalha. Nesse trabalho apresenta-se um modelo matemático da interação do rotavírus com o sistema imunológico. O principal objetivo desse estudo é avaliar, comparativamente, o desempenho das respostas imunológicas humoral e celular. Com esse intuito analisa-se o modelo proposto, composto de equações diferenciais ordinárias não lineares de primeira ordem, para avaliar a ação do sistema imunológico a fim de eliminar o rotavírus.
\end{abstract}

Palavras-chave. rotavírus, sistema imunológico, modelo matemático, infecção.

\section{Introdução}

Praticamente todas as crianças com menos de 5 anos são vítimas da infecção causada por rotavírus e as estatísticas indicam mais de 600.000 óbitos a cada ano provocados por este vírus. A via fecal-oral se constitui na principal via de transmissão do rotavírus, com a eliminação de até 1 trilhão de partículas virais por milímetro de fezes, sendo que a dose infectante pode ser com apenas 10 partículas virais. Ele provoca vômito seguido de uma diarréia tão aguda que, se não houver tratamento, pode levar a desidratação grave seguida de choque. O período de incubação é de 1 a 3 dias [8].

O rotavírus é um vírus da família reoviridae, as partículas completas compreendem 3 camadas protéicas concêntricas: capsídeo externo, intermediário e interno. O genoma viral é constituído por 11 segmentos de RNA fita dupla, que têm a ele associado a enzima transcriptase. Das 12 proteínas do rotavírus, 6 são estruturais, denominadas VPs(VP1-VP4, VP6 e VP7), e outras 6 não estruturais, as NSPs(NSP1-NSP6) [8].

\footnotetext{
${ }^{1}$ Apoio financeiro FAPESP (Projeto temático).

${ }^{2}$ Bolsista FAPESP (andresssacvel@yahoo.com.br).

${ }^{3}$ Bolsista CNPq (hyunyang@ime.unicamp.br).
} 
O rotavírus ataca as células epiteliais que recobrem o intestino delgado. Após a adsorção à célula hospedeira, a penetração viral se dá por passagem direta através da membrana celular e liberação do nucleocapsídeo no citoplasma. No fagossoma ocorre a perda do capsídeo externo e, conseqüentemente, a liberação de seu cerne no citoplasma celular. Os rotavírus usam sua RNA polimerase (que está empacotada dentro da partícula viral) para transcrever RNAm viral enquanto o genoma viral ainda está dentro do ambiente protegido pelas duas camadas do vírus. Os filamentos do RNAm viral produzidos pela polimerase são, então, mandados para o citoplasma onde ocorre a tradução do RNAm em seis proteínas estruturais e seis não estruturais. Para o empacotamento dos novos genomas virais, os 11 segmentos de RNAm viral necessários para um genoma completo se juntam e são associados com proteínas que formam a camada interna do novo vírus [11]. As fitas de RNA (+) assumem papel de molde para a produção de novas fitas de RNA (-), daí resultando RNA de dupla fita da progênie viral, e os vírus incompletos ganham mais uma camada de proteína. A montagem das partículas virais ocorre em estrutura amorfa denominada viroplasma. Após a formação da partícula viral incompleta, estas deixam o viroplasma e passam para o interior do retículo endoplasmático rugoso por brotamento, onde estão alocadas as proteínas do capsídeo externo e onde adquirem o capsídeo externo, juntamente com um envoltório transitório que depois se perde durante essa passagem. Essas são as partículas virais maduras e, finalmente, o ciclo termina quando a progênie viral é liberada por lise celular [10].

Embora mecanismos imunológicos que envolvem todo o processo desencadeado por uma infecção de rotavírus não sejam ainda bem compreendidos, sabemos que o sistema imunológico é um dos sistemas mais complexos que existem na natureza, sendo sua principal função fornecer proteção ao organismo contra uma infinidade de agentes patogênicos (vírus, bactérias, moléculas estranhas). Existem 2 tipos diferentes de mecanismos de defesa: os mecanismos de defesa não específica e específica.

Os agentes patogênicos são impedidos de entrar no organismo, ou são destruídos quando conseguem entrar, pelo mecanismo de defesa não específica, também designado por imunidade inata. Seus componentes de defesa são as barreiras físicas, fagocitose, sistema de complemento, interferon e células NK ("Natural Killers"). A resposta imunológica específica refere-se à proteção que um hospedeiro desenvolve quando sofre exposição a determinados agentes patogênicos e pode ser mediada por anticorpos (imunidade humoral) ou mediada por células (imunidade celular) [1].

Investigações compreendendo modelos animais e experimentos in vitro revelam que imunoglobulinas séricas (IgG ou IgA) e anticorpos neutralizantes parecem exercer papel protetor contra a rotavirose. Duas proteínas da superfície do vírus, VP4 e VP7, são alvos de anticorpos neutralizantes que podem prevenir o vírus de se ligar à célula alvo e penetrar, bem como os anticorpos induzidos pela proteína VP6, considerada a mais imunogênica e refletem o potencial neutralizante da IgA na mucosa do intestino delgado [2], [7]. O papel da resposta imunológica mediada por células tem sido pouco elucidado, com modelos animais constituindo a base dos estudos. Durante a infecção primária, os linfócitos T CD8+ tem um papel importante na resolução viral, bem como na proteção parcial contra reeinfecção. Os linfócitos T CD4+ são essenciais para o desenvolvimento de IgA intestinal específica contra ro- 
tavírus. A resposta celular gerada pelos linfócitos $\mathrm{T}$ parece transitória e de baixa intensidade [7].

A severidade da doença decresce com infecções subseqüentes e tanto as sintomáticas quanto as assintomáticas são igualmente efetivas em estimular a imunidade protetora. O conceito vigente sustenta que a infecção primária por rotavírus induz resposta imunológica de caráter predominantemente homotípico (sorotipoespecífico). A imunidade heterotípica estaria relacionada com reinfecções com tipos diferentes de rotavírus. No entanto, isso não foi observado em todos os estudos e há também evidências da proteção heterotípica contra doença severa depois da infecção com um único sorotipo. É importante observar que reinfecções envolvendo o mesmo sorotipo confirmam a hipótese de que a proteção da infecção natural parece ser transitória e/ou incompleta [2], [7].

\section{Modelagem Matemática}

Quando um parasita invade o organismo humano, ele busca um local apropriado para sua replição. Supondo que o sistema imunológico do hospedeiro seja incapaz de responder ao estímulo antigênico, é possível estudar a dinâmica intrínseca do parasita e, após sua compreensão, incorporar a ação do sistema imunológico nesta dinâmica. Assim, baseado em [3], a dinâmica do parasita pode ser descrita por meio do seguinte diagrama de fluxo:

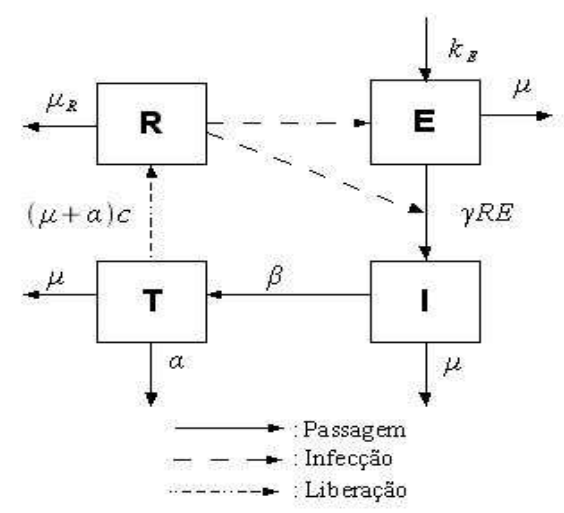

Figura 1: Diagrama de fluxo e influência das quatros populações.

onde as variáveis $R, E, I$ e $T$ são as concentrações, por $m m^{3}$, no instante de tempo $t$, de rotavírus, células epiteliais, células infectadas e células no estado terminal, respectivamente.

Os estudos sobre a interação do rotavírus com o sistema imunológico apontam para uma resposta imunológica mediada principalmente por anticorpos. No entanto, durante uma infecção inicial os linfócitos B precisam ser ativados para, então, se 
proliferar e diferenciar em plasmócitos e produzir anticorpos. Esse processo geralmente leva uma semana ou mais, nesse tempo centenas de células foram infectadas e produziram novos vírus. Embora os anticorpos, quando chegam ao cenário da infecção, sejam muito efetivos contra os novos vírus produzidos, eles tem capacidade limitada para destruir os vírus que já entraram na célula [1], [11]. Por isso, em uma infecção por rotavírus, uma boa atuação do sistema inato, que é a primeira linha de combate, é muito importante para manter a infecção em níveis baixos.

O sistema inato pode lidar com vários tipos de antígenos, mas seus principais mecanismos contra os vírus, especificamente, são o interferon e as células NK [1]. Os interferons são proteínas de aviso produzidas por células infectadas, eles induzemnas a sintetizar enzimas que levam ao bloqueio da replicação viral ou podem, ainda, sinalizar a presença do vírus para as células vizinhas, que ainda não foram infectadas, para que estas resistam a infecção viral. O interferon é capaz de ativar o potencial citolítico das células NK e pode estimular os linfócitos T. Um dos estímulos para a produção de interferon é a presença de RNA fita dupla nas células, portanto, era de se esperar que o rotavírus induzisse grande produção de interferon durante sua replicação nas células, porém, como o rotavírus mantém seu RNA dupla fita viral dentro de duas camadas protéicas durante todo o processo de replicação, as células hospedeiras demoram a produzir interferon e esta é uma maneira do vírus evadir as defesas do sistema inato [1], [11].

Assim, vamos considerar as células do compartimento I em um estado "latente", ou seja, o vírus acaba de se instalar na célula hospedeira e está preparando seu mecanismo de replicação, de forma que, ainda não é produtivo e nem está "visível" para os mecanismos de defesa citotóxicos do sistema inato. Por outro lado, o compartimento $\mathrm{T}$ concentra as células que já estão produzindo novos vírus, cuja replicação já é intensa dentro delas e, portanto, já está "visível" para o sistema inato. Por isso este é o compartimento sobre o qual o sistema imunológico vai agir. Assim passamos a considerar um compartimento S que será a concentração, por $m m^{3}$, no instante de tempo $t$, de células do sistema imunológico representado pelas respostas humoral, celular e componentes do sistema inato.

Portanto, o seguinte modelo matemático, com 5 compartimentos, descreve a dinâmica da resposta imunológica humana pela introdução do rotavírus:

$$
\left\{\begin{array}{l}
\frac{d R}{d t}=(\mu+\alpha) c T-\epsilon S R-\mu_{R} R \\
\frac{d E}{d t}=k_{E}-\gamma R E-\mu E \\
\frac{d I}{d t}=\gamma R E-\beta I-\mu I \\
\frac{d T}{d t}=\beta I-(\mu+\alpha) T-\sigma S T \\
\frac{d S}{d t}=k_{S}+\varphi T-\mu_{S} S .
\end{array}\right.
$$

As taxas $\mu_{R}, \mu_{S}$ e $\mu$ que aparecem no sistema, são de mortalidade natural dos rotavírus, células do sistema imunológico e células epiteliais em qualquer estado, respectivamente, portanto tem dimensão $[\text { tempo }]^{-1}$. A taxa $\alpha$ é de mortalidade das 
células no estado terminal por ação do vírus e também tem dimensão [tempo] ${ }^{-1} \cdot k_{E}$ e $k_{S}$ são as taxas de reposição das células epiteliais e do sistema imunológico, respectivamente, um valor constante para manter constante a população de células pela homeostasia. Estes parâmetros têm dimensão [concentração de cél.] $\times$ [tempo] $^{-1}$. A taxa de ataque às células epiteliais pelos rotavírus é representada por $\gamma$ e tem dimensão [concentração de vírus $]^{-1} \times[\text { tempo }]^{-1}$. $\beta$ é a taxa de transferência das células epiteliais infectadas para o estado terminal, cuja dimensão é [tempo] $]^{-1}$. As taxas $\epsilon$ e $\sigma$ são de desativação dos rotavírus e células no estado terminal, pela ação do sistema imunológico, respectivamente. A dimensão destas taxas é

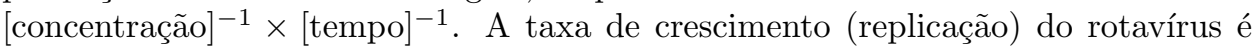
dada por $(\mu+\alpha) c$, são as células em estado terminal que, quando mortas, liberam novos vírus e $c$ é a constante indicando a quantidade de novos vírus liberados pela quantidade de células no estado terminal que morrem. Por fim, $\varphi$ representa a taxa de proliferação das células do sistema inato, que é dada pela quantidade de células em estado terminal ou mortas, sua dimensão é [tempo] ${ }^{-1}$.

\section{Pontos de Equilíbrio}

O equilíbrio trivial do sistema de equações, o qual corresponde a situação de ausência do rotavírus ou por não ter ocorrido infecção ou subseqüente a uma resposta imunológica bem sucedida, é dado por $P_{0}=(\bar{R}, \bar{E}, \bar{I}, \bar{T}, \bar{S})$, ou seja, $P_{0}=\left(0, \frac{k_{E}}{\mu}, 0,0, \frac{k_{S}}{\mu_{S}}\right)$.

A estabilidade de $P_{0}$ é determinada pelos autovalores correspondentes à matriz jacobiana associada ao sistema de equações (2.1) calculada em $P_{0}$. Mostra-se sem dificuldades que $P_{0}$ é local e assintóticamente estável se $\gamma<\gamma_{0}$, onde

$$
\gamma_{0}=\frac{\left[\mu_{R}+\left(\frac{k_{S}}{\mu_{S}}\right) \epsilon\right](\beta+\mu)\left[(\alpha+\mu)+\left(\frac{k_{S}}{\mu_{S}}\right) \sigma\right]}{c\left(\frac{k_{E}}{\mu}\right) \beta(\mu+\alpha)}=\gamma_{0}(\epsilon, \sigma) .
$$

Note que $\left(\frac{k_{S}}{\mu_{S}}\right)$ representa a concentração das células do sistema imunológico no equilíbrio. Essas células de defesa estão a postos para agir contra uma infecção. $\epsilon$ e $\sigma$ são as taxas de desativação, pela ação do sistema imunológico, dos rotavírus e células epiteliais em estado terminal, respectivamente. Essas taxas influenciam diretamente no aumento de $\gamma_{0}$. Se $\epsilon \rightarrow 0$ e $\sigma \rightarrow 0$ então $\gamma_{0}$ decresce e $\bar{\gamma}=\gamma_{0}(0,0)=\frac{\left(\mu_{R}\right)(\beta+\mu)}{c\left(\frac{k_{E}}{\mu}\right) \beta}$. Assim,

$$
\Gamma_{0}=\frac{\gamma}{\gamma}=\frac{\beta}{(\beta+\mu)} \frac{c \gamma\left(\frac{k_{E}}{\mu}\right)}{\mu_{R}} .
$$

Observe que $\beta$ é a taxa de transferência das células infectadas para o estado terminal e $\mu$ é a mortalidade natural das células epiteliais em qualquer estado, então $\frac{1}{(\beta+\mu)}$ é o período médio de sobrevivência de uma célula no estado infectado, mas não detectada pela defesa imunológica, que não morreu naturalmente. Portanto $\frac{\beta}{(\beta+\mu)}$ é a probabilidade de que uma célula sobreviva ao período infectado e entre no estado terminal. Temos que $\mu_{R}$ é a taxa de "mortalidade natural" do rotavírus, $\gamma$ é a taxa de infecção, $\left(\frac{k_{E}}{\mu}\right)$ é a concentração de células epiteliais suscetíveis no organismo e $c$ 
é a quantidade de vírus liberados por uma célula terminal morta naturalmente ou por ação do vírus. Assim, $\frac{c \gamma\left(\frac{k_{E}}{\mu}\right)}{\mu_{R}}$ será a quantidade de células epiteliais infectadas por $c$ vírus durante a "vida média" do vírus. Portanto, $\Gamma_{0}$ é o número médio de células epiteliais infectadas, na ausência de resposta imunológica, a partir de uma célula infectada que libere $c$ vírus. Se $\epsilon \rightarrow \infty$ e/ou $\sigma \rightarrow \infty$ então, $\gamma_{0} \rightarrow \infty$. Note que

$$
\Gamma=\frac{\gamma}{\gamma_{0}}=\frac{\beta}{(\beta+\mu)} \frac{(\alpha+\mu) c}{\left[(\alpha+\mu)+\left(\frac{k_{S}}{\mu_{S}}\right) \sigma\right]} \frac{\gamma\left(\frac{k_{E}}{\mu}\right)}{\left[\mu_{R}+\left(\frac{k_{S}}{\mu_{S}}\right) \epsilon\right]} .
$$

Já explicitamos a interpretação de $\frac{\beta}{(\beta+\mu)}$. Agora temos $(\alpha+\mu)$ que é composto pelas taxas de mortalidade por ação do vírus e natural, respectivamente, de uma célula no estado terminal. Existem $\left(\frac{k_{S}}{\mu_{S}}\right)$ células de defesa circulando no organismo, que podem eliminar o vírus. Assim, há "morte adicional" de $\left(\frac{k_{S}}{\mu_{S}}\right) \sigma$ de células no estado terminal, devido ao encontro com células de defesa. Logo, $\frac{1}{(\alpha+\mu)+\left(\frac{k_{S}}{\mu_{S}}\right) \sigma}$ é o período médio de sobrevivência de uma célula no estado terminal que nã̃o foi desativada pela ação do sistema imunológico, mortalidade natural ou ação do vírus. E, $\frac{(\alpha+\mu)}{(\alpha+\mu)+\left(\frac{k_{S}}{\mu_{S}}\right) \sigma} c$ é a probabilidade de uma célula terminal morrer "produtivamente" e liberar $c$ vírus, sem que seja desativada pelo sistema imunológico. Note que no caso anterior, em que $\sigma=0$, essa expressão era $c$. Há "morte adicional" de $\left(\frac{k_{S}}{\mu_{S}}\right) \epsilon$ de vírus devido ao encontro com anticorpos. Logo, $\frac{1}{\mu_{R}+\left(\frac{k_{S}}{\mu_{S}}\right) \epsilon}$ é o período médio de sobrevivência do rotavírus que não foi destivado pela "mortalidade natural" ou pela ação do sistema imunológico. Finalmente, $\frac{\gamma\left(\frac{k_{E}}{\mu}\right)}{\mu_{R}+\left(\frac{k_{S}}{\mu_{S}}\right) \epsilon}$ é o risco de infecção das células epiteliais sãs, por parte de um vírus, durante sua "vida média", sem ser desativado pela ação de anticorpos.

Portanto $\Gamma$ vai nos dar o número médio de células epiteliais que são infectadas na presença da resposta imunológica, a partir de uma célula infectada que libere $c$ vírus. Se $\Gamma \leq 1$ a infecção será debelada, caso contrário, a infecção se estabelecerá.

O equilíbrio não trivial do sistema de equações (2.1), o qual representa a coexistência de todas as variáveis que compõem o modelo, é dado por $P_{1}=(\bar{R}, \bar{E}, \bar{I}, \bar{T}, \bar{S})$, onde

$$
\begin{gathered}
\bar{R}=\frac{\mu_{S}(\mu+\alpha) c \bar{T}}{\left(\mu_{S} \mu_{R}+k_{S} \epsilon\right)+\epsilon \varphi \bar{T}}, \quad \bar{E}=\frac{k_{E}\left(\left(\mu_{S} \mu_{R}+k_{S} \epsilon\right)+\epsilon \varphi \bar{T}\right)}{\gamma \mu_{S}(\mu+\alpha) c \bar{T}+\mu\left[\left(\mu_{S} \mu_{R}+k_{S} \epsilon\right)+\epsilon \varphi \bar{T}\right]}, \\
\bar{I}=\frac{k_{E} \gamma \mu_{S}(\mu+\alpha) c \bar{T}}{(\beta+\mu)\left(\gamma \mu_{S}(\mu+\alpha) c \bar{T}+\mu\left[\left(\mu_{S} \mu_{R}+k_{S} \epsilon\right)+\epsilon \varphi \bar{T}\right]\right)}, \quad \bar{S}=\frac{k_{S}+\varphi \bar{T}}{\mu_{S}}
\end{gathered}
$$

e o valor de $\bar{T}$ é obtido como raízes positivas da equação de segundo grau

$$
a_{0} \bar{T}^{2}+a_{1}{ }^{*} \bar{T}+a_{2}{ }^{*}=0
$$


cujos coeficientes são dados por

$$
\begin{aligned}
& a_{0}{ }^{*}=\sigma \varphi[(\beta+\mu)]\left[\gamma \mu_{S}(\alpha+\mu) c+\mu \epsilon \varphi\right] \\
& a_{1}{ }^{*}=[(\beta+\mu)]\left[\left(\gamma \mu_{S}(\alpha+\mu) c+\mu \epsilon \varphi\right)\left(\mu_{S}(\mu+\alpha)+\sigma k_{S}\right)+\mu \varphi \sigma\left(\mu_{S} \mu_{R}+k_{S} \epsilon\right)\right] \\
& a_{2}{ }^{*}=\left[\gamma_{0}-\gamma\right]\left[c \mu_{S}{ }^{2} k_{E} \beta(\mu+\alpha)\right] .
\end{aligned}
$$

A natureza e número de soluções biologicamente viáveis são determinados por estes coeficientes. Facilmente vemos que $a_{0}{ }^{*}>0$ e $a_{1}{ }^{*}>0$ e, pela regra dos sinais de Descarte, basta analisar o sinal de $a_{2}{ }^{*}$. Para $\gamma<\gamma_{0}$ temos que $a_{2}{ }^{*}$ é positivo, então não existe raíz real. Para $\gamma>\gamma_{0}$ temos que $a_{2}{ }^{*}$ é negativo, então existe uma única raíz real positiva. Então o valor não-trivial $\bar{T}$ biologicamente viável existe para $\gamma>\gamma_{0}$ e é único.

A análise de estabilidade de $P_{1}$ é feita numericamente, comprovando que $P_{1}$ é local e assintoticamente estável para $\gamma>\gamma_{0}$.

\section{Comparação das Respostas Humoral e Celular}

Reescrevemos $\Gamma$, tal que, $\Gamma=\frac{\beta}{(\beta+\mu)} g(\sigma) f(\epsilon)$, onde

$$
g(\sigma)=\frac{(\alpha+\mu) c}{(\alpha+\mu)+\left(\frac{k_{S}}{\mu_{S}}\right) \sigma} \quad \text { e } \quad f(\epsilon)=\frac{\gamma\left(\frac{k_{E}}{\mu}\right)}{\mu_{R}+\left(\frac{k_{S}}{\mu_{S}}\right) \epsilon},
$$

cujas interpretações foram dadas na seção anterior.

Supondo que não haja uma resposta imunológica, isto é, $\epsilon=\sigma=0$, neste caso $g(0)=c$, quantidade de células liberadas por uma célula $T$, e $f(0)=\frac{\gamma\left(\frac{k_{E}}{\mu_{R}}\right)}{\mu_{R}}$, que é o risco de infecção das células epiteliais livres, por parte de um vírus, sem a ação de anticorpos. A partir daí, e incluindo este caso, uma relação entre $f$ e $g$ se estabelece, tal que, podemos ter $g(\sigma) \leq f(\epsilon)$ ou $g(\sigma) \geq f(\epsilon)$, conforme $\epsilon$ e $\sigma$ variam positivamente.

Se $\mu_{R}<(\alpha+\mu)$, a "mortalidade natural" do vírus é pequena comparada a "mortalidade produtiva", logo, as células terminais estão morrendo rapidamente por ação do vírus, não dando tempo da resposta celular agir sobre elas, além disso, a maioria dos vírus sobrevive e está apto a infectar. Esta condição nos remete ao cenário apresentado no gráfico $(a)$ da Figura 2, onde a curva $f(\epsilon)$ pode assumir 3 posições diferentes em relação a $g(\sigma)$, dependendo do intervalo em que o risco inicial se encontra. Nesta situação tem-se $c \leq \frac{\gamma\left(\frac{k_{E}}{\mu}\right)}{\mu_{R}}$ e $\frac{c(\alpha+\mu)}{\mu_{R}}>\frac{\gamma\left(\frac{k_{E}}{\mu}\right)}{\mu_{R}}$, onde o esforço da resposta humoral se mostra maior do que o da resposta celular, para o controle da infecção.

Se $\mu_{R}>(\alpha+\mu)$, a "mortalidade natural" do vírus é grande comparada a "mortalidade produtiva", logo, as células terminais estão morrendo pouco por ação do vírus, não estão sendo tão "produtivas", assim a resposta celular tem mais chance de agir, além disso, poucos vírus sobrevivem e estão aptos a infectar. Esta condição nos remete ao cenário apresentado no gráfico $(b)$ da Figura 2. Nesta tem-se 
$c \geq \frac{\gamma\left(\frac{k_{E}}{\mu_{R}}\right)}{\mu_{R}}$ e $\frac{c(\alpha+\mu)}{\mu_{R}}<\frac{\gamma\left(\frac{k_{E}}{\mu_{R}}\right)}{\mu_{R}}$, onde o esforço da resposta celular se mostra maior do que o da resposta humoral, para o controle da infecção.

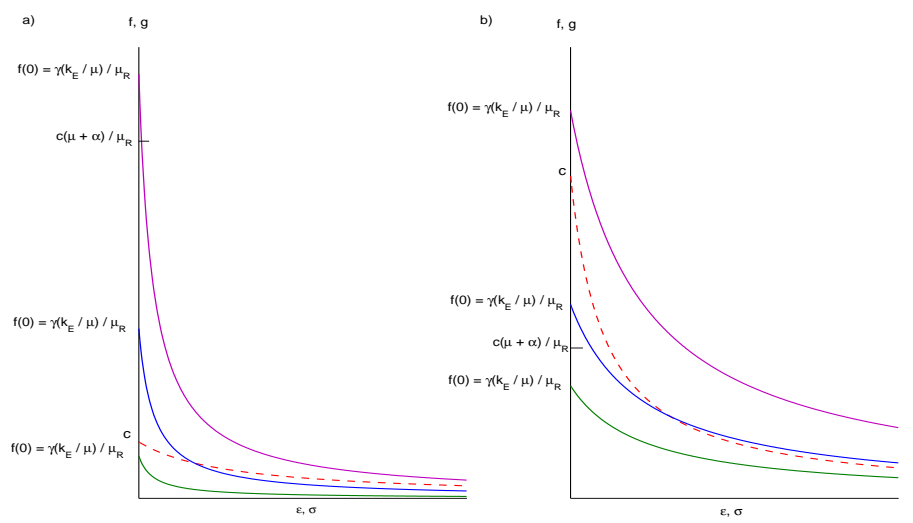

Figura 2: Gráfico qualitativo da relação entre as respostas humoral e celular. As curvas contínuas representam $f(\epsilon)$ em 3 posições diferentes. A curva tracejada representa $g(\sigma)$. $\operatorname{Em}(a)$ temos $\mu_{R}<(\alpha+\mu)$. Em $(b)$ temos $\mu_{R}>(\alpha+\mu)$.

Vamos fazer a análise da eficiência das ações humoral e celular do sitema imunológico isoladamente. Se tomarmos $\Gamma=1$ obtemos

$$
\epsilon=\frac{\beta}{(\beta+\mu)} \frac{(\alpha+\mu) c}{\left[(\alpha+\mu)+\left(\frac{k_{S}}{\mu_{S}}\right) \sigma\right]} \frac{\gamma\left(\frac{k_{E}}{\mu}\right)}{\left(\frac{k_{S}}{\mu_{S}}\right)}-\frac{\mu_{R}}{\left(\frac{k_{S}}{\mu_{S}}\right)},
$$

$\mathrm{Ou}$

$$
\sigma=\frac{\beta}{(\beta+\mu)} \frac{(\alpha+\mu) c}{\left(\frac{k_{S}}{\mu_{S}}\right)} \frac{\gamma\left(\frac{k_{E}}{\mu}\right)}{\left[\mu_{R}+\left(\frac{k_{S}}{\mu_{S}}\right) \epsilon\right]}-\frac{(\alpha+\mu)}{\left(\frac{k_{S}}{\mu_{S}}\right)} .
$$

O gráfico qualitativo, apresentado na Figura 3, mostra a relação de $\epsilon$ e $\sigma$ com a curva $\Gamma=1$, obtendo duas regiões. Os pontos $\bar{\epsilon}$ e $\bar{\sigma}$ são as interseções da curva $\Gamma=1$ com os eixos de variação de $\epsilon$ e $\sigma$. A região II representa o controle da infeç̧ão, isto é, a região de ausência do vírus. Logo, a região I, abaixo da curva $\Gamma=1$, representa a região onde existe a presença do vírus. Através desta análise, dado um $\sigma$, saberíamos que $\epsilon$ tomar para que houvesse controle da infecção, ou, dado um $\epsilon$, saberíamos que $\sigma$ tomar para que houvesse o controle.

Para obtermos a expressão para $\bar{\sigma}$, basta que, na equação 4.1, seja $\epsilon=0$, então $\bar{\sigma}=\left(\Gamma_{0}-1\right) \frac{(\alpha+\mu)}{\left(\frac{k_{S}}{\mu_{S}}\right)}$. Quanto maior o valor de $\alpha$ significa que as células terminais estão morrendo mais rápido, então a resposta imunológica celular precisa ser mais forte para conseguir destruir estas células a tempo, isto é, antes de morrerem liberando vírus. Portanto quanto maior o valor de $\alpha$, maior é o valor de $\sigma$. 
Para obtermos a expressão para $\bar{\epsilon}$, basta que, na equação 4.2 , seja $\sigma=0$, então $\bar{\epsilon}=\left(\Gamma_{0}-1\right) \frac{\mu_{R}}{\left(\frac{k_{S}}{\mu_{S}}\right)}$. Quanto maior o valor de $\mu_{R}$ menos vírus vão estar circulando no organismo e também, como $\mu_{R}$ está no denominador de $\Gamma_{0}, \Gamma_{0}$ vai diminuir, isto é, menos células vão ser infectadas, assim, com poucos vírus, a resposta imunológica humoral pode ser fraca e, ainda assim, controlar a infecção. Quanto menor o valor de $\mu_{R}$, mais vírus estarão circulando no organismo, $\Gamma_{0}$ aumenta indicando que mais células estão sendo infectadas e a resposta humoral vai ter que ser forte. Portanto quanto menor o valor de $\mu_{R}$, maior é o valor de $\epsilon$.

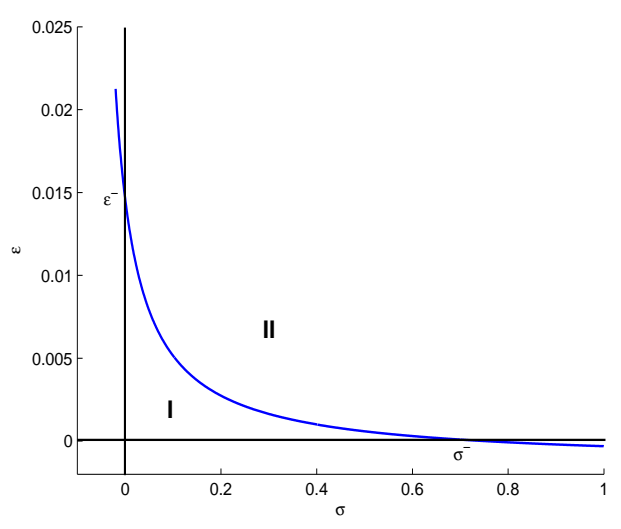

Figura 3: Região I: presença do vírus. Região II: ausência do vírus

\section{Discussão e Conclusões}

O modelo que descreve a interação do rotavírus com o sistema imunológico, é diferente da maioria de modelos que descreve outros vírus, isso justamente por uma particularidade do rotavírus que é a grande quantidade de vírus produzida em uma infecção, a constante $c$ considerada no modelo é muito grande.

As simulações numéricas são realizadas com o conjunto de parâmetros apresentados na Tabela 1.

\begin{tabular}{|c|c|c|c|c|}
\hline \hline$k_{E}$ & $k_{S}$ & $\mu$ & $\mu_{S}$ & $\varphi$ \\
\hline 1 & 0,25 & 0,0133 & 0,0333 & 0,5 \\
\hline
\end{tabular}

Tabela 1: Valores de parâmetros utilizados nas simulações [9].

A literatura a respeito de uma infecção causada por rotavírus não explicita valores para as taxas envolvidas no modelo. Um um intervalo razoável para a taxa de transferência das células infectadas para o estado terminal, $\beta$, é $[0,5 ; 1]$, 
isto acontece rápido visto que rotavírus se replicam muito, levando as células a se tornarem "produtivas" rapidamente, fazendo com que elas assumam o estado terminal. Para $\alpha$, que é a taxa de mortalidade das células no estado terminal por ação do vírus, podemos tomar o intervalo $[0,1 ; 0,5]$, ou seja, a cada 100 células no estado terminal que morrem, de 10 a 50 morrem por ação dos vírus, as demais morrem naturalmente ou por ação do sistema imunológico. Quanto a "mortalidade natural" do rotavírus, $\mu_{R}$, apenas uma pequena parcela morre desta maneira, já que este é um vírus muito resistente, como vimos no primeiro capítulo, portanto um intervalo razoável seria $[0,01 ; 0,05]$. Finalmente, para a quantidade de vírus liberados por uma célula no estado terminal que morre, $c$, podemos tomar um intervalo $[10,20]$, uma quantidade alta, que é característica destes vírus que se replicam rapidamente e em grande quantidade

Portanto, em uma infecção por rotavírus, assumindo estes intervalos de valores para os parâmetros envolvidos, percebemos que o risco de infecção das células epiteliais livres, por parte de um vírus durante sua "vida média", sem que este sofra ação de anticorpos $\left(\frac{\gamma\left(\frac{k_{E}}{\mu}\right)}{\mu_{R}}\right)$, é menor do que a quantidade de vírus liberados por célula $T$ que morre $(c)$. Isso nos leva a pensar que a resposta celular teria, então, um esforço maior para controlar a infecção, no entanto, temos que $(\mu+\alpha)>\mu_{R}$, isto é, a "mortalidade produtiva" é maior que a "mortalidade natural" do vírus. As células terminais estão morrendo por ação do vírus rapidamente, tal que a resposta celular não está tendo tempo de agir antes que a célula morra liberando novos vírus. Assim, muitos vírus são liberados e sobrevivem às adversidades do meio, estando aptos a infectar. Portanto, a ação de anticorpos no controle da infecção é essencial, isso ficará claro nas simulações numéricas.

A Figura 4 considera os valores dos parâmetros respeitando as características peculiares do rotavírus. O resultado disto é que a queda da curva $f(\epsilon)$ é mais acentuada do que a da curva $g(\sigma)$, como mostra a figura 4(a), demonstrando que o esforço da resposta humoral é maior do que o da resposta celular, para controlar a infecção. E também, através da figura 4(b), podemos perceber que o valor de $\epsilon$, quando $\sigma=0$, é aproximadamente 0,0179 , enquanto que o valor de $\sigma$, quando $\epsilon=0$, é aproximadamente 0,2032 . Isto descreve uma situação em que, isoladamente, a resposta humoral controla melhor a infecção causada por rotavírus, do que a resposta celular.

\footnotetext{
Abstract. In infants and young children, rotavirus is the major cause of severe inflammation of the intestine (gastroenteritis). This virus causes nearly a million deaths each year worldwide, mostly in developing countries. The complex biology of rotavirus and its interaction with the immune system are the motivation of this work, that presents a model for this interaction, structured by non-linear ordinary differential equations of first-order that describes the action of the innate immune system to eliminate rotavirus. From this model, we analyze, comparatively, the humoral and cellular responses.
} 


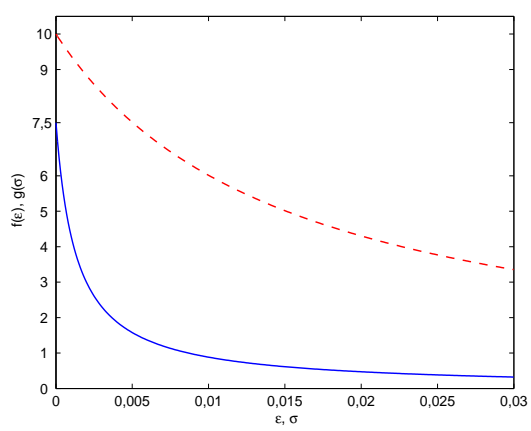

(a)

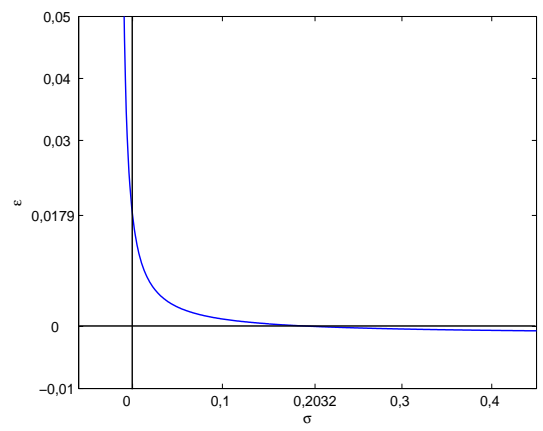

(b)

Figura 4: A curva tracejada corresponde a $g(\sigma)$ e a contínua representa $f(\epsilon)$. Utilizamos os valores apresentados na Tabela 1 e para os parâmetros: $\alpha=0,1, \mu_{R}=0,01, \beta=0,5$, $c=10, \epsilon=\sigma=0,1$ e $\gamma=0,0009975$

\section{Referências}

[1] A.K. Abbas, A.H. Lichtman, J.S. Pober, "Imunologia Celular e Molecular",5 ed, Revinter, Rio de Janeiro, 2003.

[2] J. Angel, M.A. Franco, H.B. Greenberg, Rotavirus vaccines:recent developments and future considerations, Nature Reviews Microbiology, 5, No. 7 (2007), 529539.

[3] S. Barrozo, H.M. Yang, Desenvolvimento de um modelo para resposta imunlógica primária célula-mediada, TEMA - Tend. Mat. Apl. Comput., 7, No. 1 (2006), 31-41.

[4] S. Barrozo, H.M. Yang, Mecanismos da interação antígeno-anticorpo em uma resposta primária célula T-mediada, TEMA - Tend. Mat. Apl. Comput., 7, No. 1 (2006), 43-52.

[5] J.R. Coura, "Dinâmica das doenças infecciosas e parasitárias", v. 2, Guanabara Koogan, Rio de Janeiro, 2005.

[6] L. Edelstein-Keshet, "Mathematical Models in Biology", Birkhauser Mathematics Series, 1988.

[7] C.K. Farhat, L.H.F.R. Carvalho, R.C. de Menezes Succi, "Infectologia Pediátrica", Ed. 3, Editora Atheneu, São Paulo, 2007.

[8] R.I. Glass, Combate ao Rotavírus, Scientific American Brasil, ed 48, maio de 2006.

[9] A.C. Guyton, J.E. Hall, "Tratado de Fisiologia Médica", 10 ed., Guanabara Koogan, Rio de Janeiro, 2002. 
[10] J.D.P. Mascarenhas, "Caracterização molecular de genotipos de rotavírus do grupo A em Belém,Pará, no período de 1990 a 2003: estudo em neonatos, crianças diarréicas de 0 e 3 anos e ensaio clínico com vacinas", Tese de Doutorado, Instituto Oswaldo Cruz, Rio de Janeiro, 2006.

[11] L. Sompayrac, "How Pathogenic Viruses Work", Janes and Bartlett, Canadá, 2002. 